\title{
DESAIN KEMASAN BAHAN DAPUR BERBENTUK SERBUK DENGAN MENGGUNAKAN PENDEKATAN KANSEI ENGINEERING
}

\author{
Alifta Dicasani ${ }^{1}$, Hari Purnomo \\ Magister Teknik Industri, Fakultas Teknologi Industri, Universitas Islam Indonesia ${ }^{1,2)}$, \\ Jl. Kaliurang Km 14,5, Sleman, Yogyakarta, 55584 \\ E-Mail : adicasani@gmail.com ${ }^{1}$, haripurnomo134@gmail.com ${ }^{2}$
}

\begin{abstract}
Herbs widely circulated in the powder form wrapped in packaging with certain dose. To make it easier to measure the dose, it needs to develop a new design. In a product design, packaging use is as a wrapper and a promotional materials to attract customers. Therefore, the need for designing is accordance with the taste and desires of the customer's psychological. Kansei Engineering approach is used to translating the customer feelings and impressions into the design parameters. The consumer criteria are identified by paper-based survey and validation test is used to test the hypothesis. Supported by the test, result of this study are able to produce packaging that satisfy the customer's psychological desires.
\end{abstract}

Keywords : Packaging, Kansei Engineering, Ergonomic, Herbs.

\section{PENDAHULUAN}

Definisi serbuk adalah partikel yang berbutir halus seperti tepung, abu atau bubuk (KBBI, t. thn). Serbuk digambarkan sebagai partikel halus suatu bahan kering dan mempunyai ukuran sangat kecil. Dewasa ini, berbagai produk telah disajikan dalam bentuk serbuk karena lebih ringkas, mudah diaplikasikan dan cenderung tidak meninggalkan residu. Salah satu produk yang banyak dikemas dalam bentuk serbuk adalah bahan dapur atau aneka bumbu dapur.

Penggunaan bahan berbentuk serbuk harus lebih berhati-hati karena sifat mampu alir yang dimiliki. Sehingga sangat memungkinkan serbuk berhamburan terbawa angin atau tumpah. Bahan serbuk yang dikemas dalam jumlah untuk beberapa kali penggunaan akan membutuhkan alat bantu takar untuk mengukur jumlah produk yang akan digunakan. Beberapa jenis bahan dapur, ketepatan takaran penggunaan menjadi hal yang sangat penting (Neti_Recipes, 2014). Selama ini proses penakaran bahan dapur yang umumnya terjadi adalah dengan cara mengambil bahan dengan sendok takar atau menuangkan bahan ke sendok takar. Namun masih terdapat masalah di kedua cara tersebut, salah satunya adalah jika keberadaan sendok takar tidak diketahui. Sehingga diperlukan perancangan desain yang menggabungkan antara kemasan bahan dapur dengan takaran ukur.

Kemasan merupakan komponen yang sangat penting dalam suatu produk, karena kemasan merupakan hal pertama yang dilihat oleh konsumen ketika akan membeli suatu produk (Cenadi, 2000). Kemasan berfungsi menjual apa yang dilindunginya sekaligus sebagai pelindung produk dari kerusakan (Kartajaya, 1996; Kementerian Perindustrian, 2012). Pengemas adalah proses tentang rancangan dan pembuatan tempat atau pembungkus untuk produk (Tjiptono, 2002). Kemasan harus dapat memberikan informasi dan komunikasi yang jelas terhadap identitas produk. Kemasan yang menarik sangat berpengaruh terhadap keputusan konsumen untuk membeli (Akrom, 2013). Sebagai penentu keberhasilan dari sebuah produk, kemasan harus dirancang berdasarkan faktor psikologis konsumen, agar lebih memikat dari sisi emosi dan perasaan. Diharapkan dengan adanya kemasan bahan dapur yang built-in dengan takaran dan sesuai dengan keinginan emosi konsumen akan berdampak positif pada produk tersebut. Rundh (2013) menjelaskan bahwa desain kemasan yang menarik dan jelas terhadap identitas produk dapat menarik konsumen untuk membeli. 
Berdasarkan uaraian diatas maka diperlukan desain kemasan bahan dapur berbentuk serbuk. Konsep desain menggunakan Kansei Engineering (KE).

Pemilihan KE dikarenakan konsep tersebut mampu menerjemahkan perasaan dan emosi konsumen ke dalam parameter produk (Nagamachi, 2002). Berbagai perancangan kemasan yang menerapkan pendekatan KE antara lain kemasan bedak tabur (Rahmayani, et al., 2015), kemasan pengharum (Djatna dan Kurniati, 2015), kemasan abon (Soewardi dan Dicasani, 2014), botol saus (Mamaghani, et al., 2014), produk kesehatan (Zeynali, et al., 2014), kemasan minuman (Huang, et al., 2013), kemasan sampo (Tesavrita, et al., 2012), dan kemasan garam mandi (Nagamachi, et al., 2008). Berdasarkan pada persoalan di atas dan dengan mempertimbangkan penelitian terdahulu, maka pada penelitian ini akan dipaparkan desain kemasan bahan serbuk ergonomis. Metode yang digunakan menggunakan pendekatan KE. Pemilihan KE bertujuan agar desain kemasan bahan serbuk dapat memenuhi kriteria konsumen.

\section{METODE PENELITIAN}

\subsection{Pengumpulan Data}

Data diperoleh menggunakan kuesioner yang disebarkan kepada para pengguna bahan dapur yang cukup aktif menggunakan bahan dapur (> 3 kali dalam satu minggu). Populasi pengguna bahan dapur sangat besar, sehingga jumlah sampel minimum ditentukan dengan formula (Supranto, 2001):

$\mathrm{n}=\frac{1}{4}\left(\frac{Z^{u} / 2}{E}\right)^{2}$

Dengan:

$\mathrm{n}=$ jumlah sampel.

$\mathrm{z}=$ angka penyimpangan nilai varians dari mean.

$\mathrm{E}=$ limit dari error atau presisi absolut.

$\alpha=$ tingkat kesalahan data yang dapat di toleransi oleh peneliti.

Dengan tingkat kepercayaan $95 \%$ maka kesalahan duga sampel sebesar 5\% $(\alpha=5 \%)$, batas error $10 \%$ maka sampel minimum 96 responden.
Kuesioner ini terdiri dari 3 bagian, yaitu: (1) identifikasi kebutuhan konsumen akan kemasan bahan dapur atau bisa disebut dengan kata kansei, (2) spesifikasi desain fisik kemasan dan (3) validasi desain usulan untuk mengetahui apakah desain yang dihasilkan sudah memenuhi keinginan konsumen.

\subsection{Konsep KE}

KE merupakan konsep yang menerjemahkan perasaan dan kesan ke dalam parameter produk (Nagamachi, 2002). Prinsip KE adalah mengidentifikasi dan menganalisis emosi manusia dan mengimplementasikan dalam parameter desain (Nagamachi and Lokman, 2011). Produk memiliki dua sifat yaitu fungsi dasar dan tambahan. Fungsi dasar produk terkait dengan kualitas, kapasitas dan penampilan. Sedangkan fungsi tambahan terkait dengan gaya dan warna yang manarik. Nagamachi (1999) mendefinisikan kedua fungsi tersebut sebagai faktor fisik dan mental. Faktor yang cukup penting untuk diperhatikan adalah faktor psikologis atau dikenal dengan human kansei. Kecenderungan konsumen untuk membeli produk karena daya tarik dari produk tersebut. Oleh karena itu, sebuah produk baru harus dapat menangkap pikiran konsumen. Produk baru yang dibuat harus mampu menterjemahkan keinginan konsumen menjadi desain yang menarik (Schutte, 2002). KE dapat digunakan untuk menterjemahkan kebutuhan tersebut. $\mathrm{KE}$ yang digunakan pada penelitian ini adalah KE tipe 1. Pada tipe ini, konsep suatu produk akan dijabarkan lebih detail hingga level tertentu dan menghasilkan spesifikasi parameter sebuah desain.

\subsection{Analisis Statistik}

Analisis statistik menggunakan non parametrik karena data berskala ordinal. Pengujian validitas dilakukan dengan metode uji Spearman's Rank Correlation (Sheskin, 2004). Sedangkan tingkat reliabilitas ditentukan dengan koefisien Alpha Cronbach dan dinyatakan reliabel jika nilai Croncbach Alpha > 0,7 (Yamin dan Kurniawan, 2009). 
Tabel 1. Hasil uji validitas

Kata Kansei

$\begin{array}{cc}\text { Mudah digunakan } & 0,444 \\ \text { Rapat } & 0,654 \\ \text { Bersih } & 0,327 \\ \text { Sederhana } & 0,526 \\ \text { Kecil } & 0,157 \\ \text { Jelas } & 0,625 \\ \text { Menarik } & 0,558 \\ \text { Awet } & 0,633\end{array}$

Tabel 2. Hasil analisis faktor

\begin{tabular}{ccc}
\hline Kata Kansei & Ilustratif & Keamanan \\
\hline Mudah digunakan & $-0,008$ & 0,891 \\
Awet & 0,363 & 0,795 \\
Rapat & 0,314 & 0,68 \\
Bersih & 0,824 & $-0,079$ \\
Jelas & 0,713 & 0,322 \\
Menarik & 0,655 & 0,395 \\
Sederhana & 0,555 & 0,371 \\
\hline
\end{tabular}

Analisis faktor pada penelitian ini digunakan untuk mengelompokan variabel keseluruhan sesuai dengan tingkat kemiripan. Untuk mengetahui kelayakan dari analisis faktor dilakukan pengujian Bartlett test of sphericty dan Kaiser Meyer Olkin (KMO) measure of sampling adequacy (Yamin dan Kurniawan, 2009). Pengujian desain akhir digunakan metode Stuart- Maxwell test of Marginal Homogeneity (Yamin dan Kurniawan, 2009) yang merupakan perluasan dari uji McNemar.

\section{HASIL DAN PEMBAHASAN}

\subsection{Kata Kansei}

Kata-kata kansei diidentifikasi melalui kuesioner terbuka terhadap 100 orang pengguna bumbu dapur. Hasil penyebaran kuesioner didapat 23 kata kansei.
Kata-kata kansei yang diperoleh kemudian dikelompokkan agar kata-kata kansei serupa atau mirip disatukan menjadi kata kansei baru yang dapat mewakili kelompok katakata kansei lama. Pengelompokan kata kansei terbentuk delapan kata kansei. Hasil pengujian reliabilitas disimpulkan bahwa kuisioner reliabel karena nilai Cronbach's Alpha : 0,768 (>0,7). Sedangkan pengujian validitas kata kansei diperoleh tujuh kata kansei yang valid atau berada di atas nilai tabel r $(>0,195)$ yaitu mudah digunakan, rapat, bersih, sederhana, jelas, menarik, dan awet. Sedangkan kata kansei kecil tidak dapat digunakan karena tidak valid $(0,157<$ tabel r). Hasil uji validitas ditunjukkan pada Tabel 1. Kata kansei yang valid ini kemudian di kelompokkan menjadi 2 konsep yang berbeda menggunakan analisis faktor dengan hasil ditunjukkan pada Tabel 2. 
Tabel 3. Pemetaan konsep zero level

Orde 0

Orde 1

Kemasan bumbu dapur

Konsep $1:$ Kemasan ilustratif

Konsep 2 : Keamanan kemasan

Tabel 4. Pemetaan konsep 1 : Kemasan ilustratif

\begin{tabular}{|c|c|c|c|c|c|}
\hline Orde 1 & Orde 2 & Orde 3 & Orde 4 & Spesifikasi fisik Desain & Kode \\
\hline $\begin{array}{l}\text { Kemasan } \\
\text { ilustratif }\end{array}$ & Bergambar & $\begin{array}{l}\text { Konten/isi } \\
\text { produk }\end{array}$ & & $\begin{array}{l}\text { Terdapat gambar dari produk (misal } \\
\text { gambar merica, bawang putih, dsb) }\end{array}$ & $\mathrm{D}$ \\
\hline & \multirow{8}{*}{ Informasi } & Merk & & Terdapat informasi merk & $\mathrm{C}$ \\
\hline & & $\begin{array}{l}\text { Nama } \\
\text { produk }\end{array}$ & & Terdapat informasi konten/produk & $\mathrm{C}$ \\
\hline & & Kadaluwarsa & & Terdapat informasi kadaluwarsa & $\mathrm{F}$ \\
\hline & & Komposisi & & Terdapat informasi komposisi bahan & $\mathrm{F}$ \\
\hline & & Produsen & & Terdapat informasi produsen & $\mathrm{F}$ \\
\hline & & $\begin{array}{l}\text { Keterangan } \\
\text { halal }\end{array}$ & & Sesuai sertifikat halal & $\mathrm{F}$ \\
\hline & & Isi bersih & & Terdapat informasi isi bersih & $\mathrm{F}$ \\
\hline & & lainnya & & $\begin{array}{l}\text { Informasi tambahan mengenai } \\
\text { produk }\end{array}$ & $\mathrm{F}$ \\
\hline & \multirow{10}{*}{ Berwarna } & $\begin{array}{l}\text { Warna } \\
\text { kemasan }\end{array}$ & & Transparan dengan tutup berwarna & E, I \\
\hline & & $\begin{array}{l}\text { Warna } \\
\text { gambar }\end{array}$ & Konten & $\begin{array}{l}\text { Menyesuaikan warna asli bahan } \\
\text { yang dikandung }\end{array}$ & $\mathrm{D}$ \\
\hline & & \multirow{8}{*}{$\begin{array}{l}\text { Warna } \\
\text { tulisan }\end{array}$} & Merk & Kontras dengan warna latar belakang & $\mathrm{C}$ \\
\hline & & & $\begin{array}{l}\text { Nama } \\
\text { produk }\end{array}$ & Kontras dengan warna latar belakang & $\mathrm{C}$ \\
\hline & & & Kadaluarsa & Kontras dengan warna latar belakang & $\mathrm{F}$ \\
\hline & & & Komposisi & Kontras dengan warna latar belakang & $\mathrm{F}$ \\
\hline & & & Produsen & Kontras dengan warna latar belakang & $\mathrm{F}$ \\
\hline & & & $\begin{array}{l}\text { Keterangan } \\
\text { halal }\end{array}$ & Sesuai sertifikat & $\mathrm{F}$ \\
\hline & & & Isi bersih & Kontras dengan warna latar belakang & $\mathrm{F}$ \\
\hline & & & lainnya & Kontras dengan warna latar belakang & $\mathrm{F}$ \\
\hline
\end{tabular}

Konsep pertama terdiri dari kata kansei bersih, jelas, menarik, dan sederhana. Keempat kata kansei tersebut diwakilkan dengan konsep kemasan ilustratif yang merupakan gambaran untuk membantu memperjelas isi. Gambaran tersebut dapat berupa tampilan desain, warna, informasi atau keterangan tambahan pada kemasan (KBBI, t. thn). Konsep kedua terdiri dari kata kansei mudah digunakan, awet dan rapat. Ketiga kata kansei ini erat kaitannya dengan keamanan.

Definisi aman menurut kamus besar bahasa indonesia yaitu bebas dari bahaya, gangguan, terlindung atau tersembunyi, pasti tidak meragukan, tidak mengandung risiko, tenteram, dan tidak merasa takut atau khawatir (KBBI, t. thn). 
Tabel 5. Pemetaan konsep 2 : Keamanan kemasan

\begin{tabular}{|c|c|c|c|c|c|c|}
\hline Orde 1 & Orde 2 & Orde 3 & Orde 4 & Orde 5 & $\begin{array}{c}\text { Spesifikasi } \\
\text { fisik Desain }\end{array}$ & Kode \\
\hline \multirow[t]{10}{*}{$\begin{array}{c}\text { Keamanan } \\
\text { kemasan }\end{array}$} & $\begin{array}{c}\text { Bagi } \\
\text { konsumen }\end{array}$ & Tidak beracun & $\begin{array}{c}\text { Bahan } \\
\text { kemasan }\end{array}$ & & Plastik PET & $\mathrm{E}$ \\
\hline & & Tidak melukai & $\begin{array}{l}\text { Tidak } \\
\text { runcing }\end{array}$ & $\begin{array}{c}\text { Model } \\
\text { kemasan }\end{array}$ & $\begin{array}{c}\text { Toples } 120 \mathrm{ml} \\
\text { (diameter } 4 \\
\mathrm{~cm}, \\
\text { tinggi } 10 \mathrm{~cm} \text { ) }\end{array}$ & $\mathrm{E}$ \\
\hline & & & Tidak tajam & $\begin{array}{c}\text { Model } \\
\text { kemasan }\end{array}$ & Toples silinder & $\mathrm{E}$ \\
\hline & & $\begin{array}{c}\text { Mudah } \\
\text { digunakan }\end{array}$ & $\begin{array}{c}\text { Sesuai } \\
\text { kebutuhan }\end{array}$ & $\begin{array}{l}\text { Terdapat } \\
\text { takaran } \\
\text { keluaran }\end{array}$ & $\begin{array}{c}\text { Built-in } \\
\text { dengan } \\
\text { takaran } 1 \mathrm{sdt}\end{array}$ & $\mathrm{G}, \mathrm{H}$ \\
\hline & & & $\begin{array}{c}\text { Cara } \\
\text { membuka }\end{array}$ & & Putar dan flip & A,B \\
\hline & $\begin{array}{l}\text { Bagi } \\
\text { produk }\end{array}$ & $\begin{array}{c}\text { Tidak } \\
\text { terkontaminasi }\end{array}$ & $\begin{array}{c}\text { Bahan } \\
\text { kemasan }\end{array}$ & & Plastik PET & $\mathrm{E}$ \\
\hline & & & $\begin{array}{l}\text { Penutup } \\
\text { kemasan }\end{array}$ & & Plastik PP & I \\
\hline & & & $\begin{array}{c}\text { Terlindungi } \\
\text { saat tidak } \\
\text { dibutuhkan }\end{array}$ & $\begin{array}{l}\text { Tutup } \\
\text { rapat }\end{array}$ & $\begin{array}{l}\text { Terdapat } 2 \text { kali } \\
\text { penutupan }\end{array}$ & A,B \\
\hline & & $\begin{array}{l}\text { Tidak mudah } \\
\text { rusak }\end{array}$ & $\begin{array}{c}\text { bahan } \\
\text { kemasan }\end{array}$ & & Plastik PET & $\mathrm{E}$ \\
\hline & $\begin{array}{c}\text { Bagi } \\
\text { lingkungan }\end{array}$ & $\begin{array}{c}\text { Tidak } \\
\text { mencemari }\end{array}$ & $\begin{array}{l}\text { Dapat } \\
\text { didaur } \\
\text { ulang }\end{array}$ & $\begin{array}{l}\text { Bahan } \\
\text { kemasan }\end{array}$ & Plastik PET & $\mathrm{E}$ \\
\hline
\end{tabular}

\subsection{Desain Usulan}

Konsep kemasan kemudian dijabarkan menjadi beberapa level hingga menemukan spesifikasi parameter desain produk. Berikut hasil pemetaan konsep kemasan menjadi parameter desain fisik kemasan yang terdapat pada Tabel 3.

Tabel 4 menjabarkan parameter fisik desain kemasan yang ilustratif. Terdapatnya gambar dan informasi mengenai konten/isi mampu mewakili kata kansei jelas. Sedangkan warna kemasan dan warna tulisan mampu mewakili kata kansei menarik, bersih dan sederhana. Tabel 5 menjabarkan parameter desain keamanan kemasan yaitu toples dengan bahan plastik PET atau PETE (Polyethylene Terephthalate) yang sesuai untuk bahan pengemas produk minuman/makanan (Marsh dan Buguse, 2007) dan plastik PP (Polypropylene) yang bersifat lebih keras sebagai penutup kemasan mampu mewakili kata kansei awet. Terdapat 2 penutup pada kemasan mampu mewakili kata kansei rapat. Kata kansei mudah digunakan direpresentasikan dengan adanya penakar pada bagian tutup yang penggunaannya dengan cara membalikkan kemasan agar serbuk memenuhi ruangan penakar. Selanjutnya memutar pembatas (lock/open) sehingga bumbu terkunci di dalam ruangan sesuai takaran dan flip untuk mengeluarkan bumbu dapur, sehingga konsumen tidak membutuhkan sendok takar lagi. Gambar 1-5 merupakan desain kemasan usulan hasil dari pemetaan konsep. 


\subsection{Validasi Desain Usulan}

Uji validasi ini dilakukan untuk menilai apakah desain yang diusulkan telah sesuai dengan keinginan konsumen. Pengujian dilakukan menggunakan Stuart Maxwell Test Of Marginal Homogeneity dengan hipotesa:
$\mathrm{H}_{1}$ : Terdapat perbedaan yang signifikan antara keinginan konsumen dengan desain kemasan.

$\mathrm{H}_{0}$ : Tidak terdapat perbedaan yang signifikan antara keinginan konsumen dengan desain kemasan.

Hasil pengujian ditunjukkan seperti pada Tabel 6.

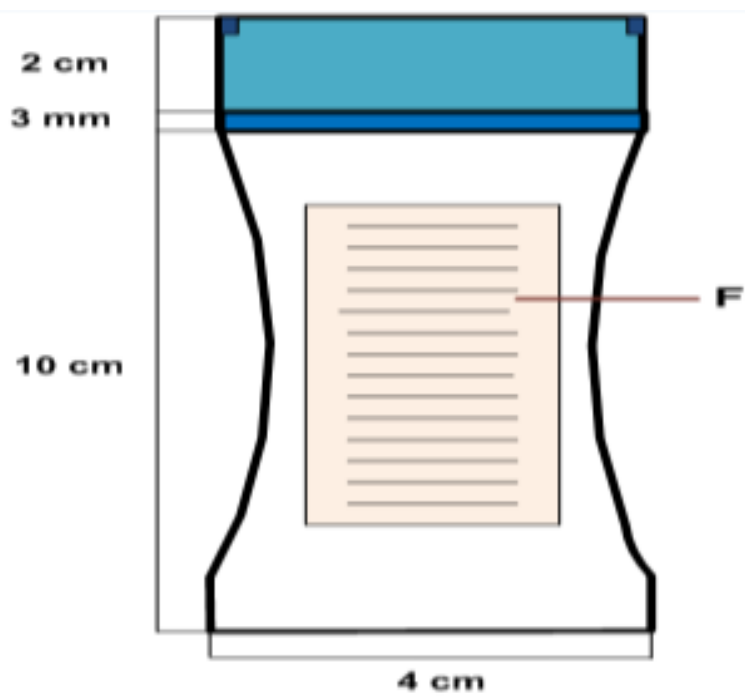

Gambar 2. Desain usulan tampak belakang.

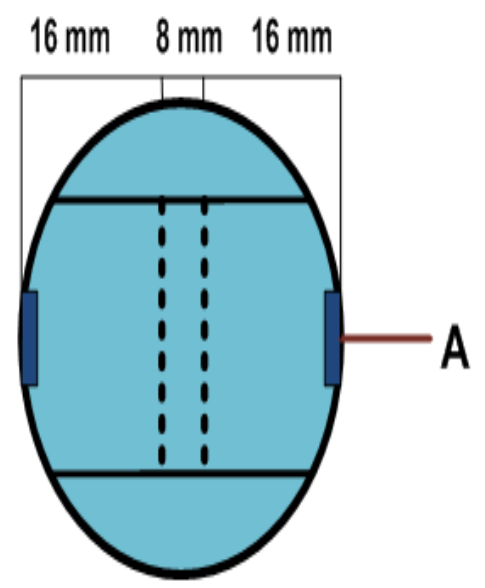

Gambar 3. Tutup tampak atas.

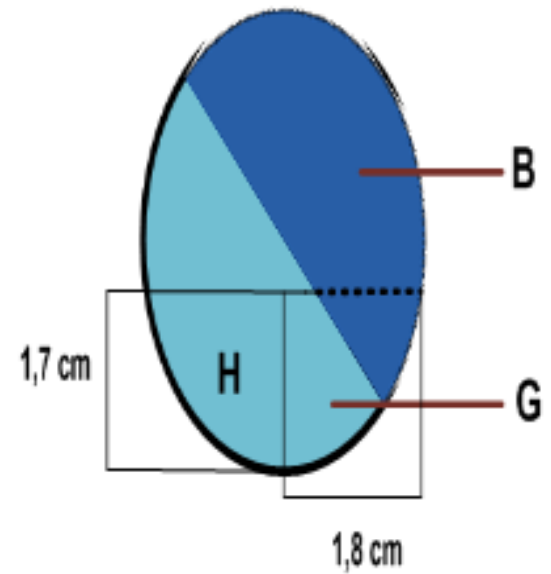

Gambar 4. Tutup tampak bawah.

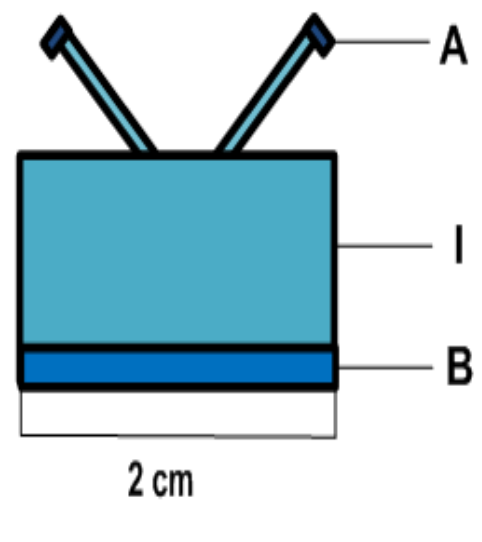

Gambar 5. Tutup tampak samping. 
Tabel 6. Uji marginal homogeneity desain usulan

Kata Kansei

\begin{tabular}{cl}
\hline Mudah Digunakan & 0,080 \\
Rapat & 0,105 \\
Bersih & 0,106 \\
Sederhana & 0,225 \\
Jelas & 0,288 \\
Menarik & 0,209 \\
Awet & 0,599 \\
\hline
\end{tabular}

Asymp. Sig. (2-tailed)
Dengan taraf signifikansi 5\%, didapat nilai $p>0,05$ yang berarti seluruh item menunjukkan bahwa tidak terdapat perbedaan antara kata kansei dengan desain yang dihasilkan atau dengan kata lain desain telah memenuhi keinginan konsumen.

\section{KESIMPULAN}

Berdasrkan hasil penelitian dapat disimpulkan bahwa kriteria konsumen terhadap kemasan bumbu dapur terdiri dari 2 konsep yaitu (1) kemasan ilustratif, yang mewakili kata kansei menarik, jelas, bersih dan sederhana; dan (2) keamanan kemasan, yang mewakili kata kansei awet, mudah digunakan dan rapat. Pada desain kemasan ini terdapat inovasi berupa penakar pada bagian tutup kemasan sehingga pada saat penggunaan akan lebih memudahkan dalam mengatur jumlah bumbu dapur yang akan digunakan. Hasil uji homogenitas antara desain usulan dengan kata kansei keinginan konsumen, terbukti bahwa perancangan desain kemasan bumbu dapur dengan menggunakan pendekatan KE mampu memenuhi kriteria konsumen dengan taraf signifikansi $5 \%$.

\section{DAFTAR PUSTAKA}

Akrom, M., C., 2013 Pengaruh kemasan, harga dan promosi terhadap proses keputusan pembelian konsumen kripik paru UMKM Sukorejo Kendal. Universitas Negeri Semarang.

Cenadi, C., S., 2000. Peranan desain kemasan dalam dunia pemasaran. NIRMANA Vol. 2, No. 1. Hal. 92103.

Djatna, T., and Kurniati, W. D., 2015. A System analysis and design for packaging design of powder shaped fresheners based on Kansei Engineering. Industrial Engineering and Service Science. IESS, p. 115123.

Huang, S.W., Yang, M.C., Liao, C.H., Lin, Y.C., 2013. A Kansei study of beverage packaging form with coffee image. Design Studies.

Kartajaya, H., 1996. Marketing Plus 2000 Siasat memenangkan persaingan global. Jakarta: PT. Gramedia Pustaka Utama. 
KBBI. (t.thn.). Kamus versi online/daring (dalam jaringan). Dipetik July 27, Tersedia di http://www.kbbi.web.id.

Kementerian Perindustrian., 2012. Pelatihan teknologi kemasan untuk penyuluh. Diakses tanggal 20 Januari 2014. Tersedia di http://www.kemenperin. go.id.

Mamaghani, N. K., Rahimian, E., Mortezaei, S.R., 2014. Kansei Engineering approach for consumer's perception of the ketchup sauce bottle. Kansei Engineering \& Emotion Research. Linkoping : Linkoping University.

Marsh, K., \& Bugusu, B., 2007. Food packaging-roles, materials and enviromental issues. Journal of Food Science, R 39-55.

Nagamachi, M., 1999. Kansei Engineering : The implication and applications to product development. Proceding of System, Man, and Cybernetic.

Nagamachi., 2002. M. Kansei Engineering as a powerful consumer - oriented technology for product development. Applied Ergonomics. 33, p. 289-294.

Nagamachi, M. \& Lokman, A. M., 2011. Inovations of kansei engineering. Boca Raton: CRC Press Taylor \& Francis Group.

Nagamachi, M., Tachikawa, M., Imanishi, N., Ishizawa, T., Yano, S., 2008. A successfull statistical procedure on Kansei Engineering products. 11th QMOD Conference. Quality Management and Organizational Development Attaining Sustainability From Organizational Excellence to Sustainable Excellence. Linkoping: Linköping University Electronic Press, Linkopings Universitet, Helsingborg, Sweden.
Neti_Recipes., 2014. Cara menakar bahanbahan di dalam resep (Satuan Ukuran). Diakses tanggal 27 Juli 2016, dari Neti Recipes-Simple Cooking with Neti. Tersedia di di http://www.netirecipes.go.id.

Rahmayani, N., Yuniar, Desrianty, A., 2015. Rancangan kemasan bedak tabur (Loose Powder) dengan menggunakan metode Kansei Engineering. Jurnal Online Institut Teknologi Nasional.

Rundh, B., 2013.Linking packaging to marketing: How packaging is influencing the marketing strategy. British Food Journal. Vol. 115 Iss:11, p.1547- 1563.

Schutte, S., 2002. Designing feeling into products integrating Kansei Engineering methodology in product development. Sweden: Linkoping University.

Sheskin, D. J., 2004. Handbook of parametric and non parametric statistical procedures Third Edition. Washington : Chapman \& Hall / CRC.

Soewardi, H. dan Dicasani., 2014. A. ergonomic packaging design of vegetable shredded by using Kansei Engineering approach. APCHI.

Supranto, J., 2001. Statistik: Teori dan Aplikasi. Jakarta: Penerbit Erlangga.

Tesavrita, C., Suryadi, D., Brachmantiyoko, Y., 2012. Perancangan ulang kemasan produk sampo dengan mempertimbangkan emosi konsumen berdasarkan metode Kansei Engineering. Seminar Nasional Ergonomi. Hal. J-15 - J20.

Tjiptono, F., 2002. Strategi pemasaran. Yogyakarta: Andi Offset. 
Yamin, S. dan Kurniawan, H., 2009. SPSS COMPLETE. Jakarta: Salemba Infotek.

Zeynali, M. A., Hasyemzadeh, G., Zandhessami, H., 2014. Determination and prioritization of product design spesifications with Kansei Engineering approach: (Case Study: Packing Designation of New Health Product of Firouz Health Group). Kuwait Chapter of Arabian Journal of Business and Management Review. 